\title{
A Brief Overview of the Coxib Drugs in the Veterinary Field
}

\author{
${ }^{1}$ Tae-Won Kim and ${ }^{2}$ Mario Giorgi \\ ${ }^{1}$ College of Veterinary Medicine, \\ Chungnam National University, Daejeon, South Korea \\ ${ }^{2}$ Department of Veterinary Science, University of Pisa, \\ Via Livornese (lato monte) 1, San Piero a Grado 56010 Pisa, Italy
}

Received 2013-05-08, Revised 2013-05-16; Accepted 2013-07-05

\begin{abstract}
Traditional Non-steroidal Anti-Inflammatory Drugs (NAIDs) have been widely used to deal with many inflammatory conditions in veterinary medicine. Nowadays however, as the quality of life of animals is improved, new drug options need to be explored. In this review, the authors report on recent trends and the application of the active ingredients labeled for veterinary purposes.
\end{abstract}

Keywords: NSAID, Coxib, Veterinary Medicine

\section{INTRODUCTION}

In basic terms, inflammation is a protective reaction of the body against external and internal stimuli. In the acute phase, it serves to remove triggering agents in addition to restoring tissue following damage. However, if the inflammatory process becomes overwhelming, it results in pain through activation of nociceptors by various inflammatory mediators and eventually it can become life threatening and requiring of clinical intervention (Dubin and Patapoutian, 2010).

The Nonsteroidal Anti-Inflammatory Drugs (NSAIDs) are used to treat pain, fever and inflammation in various diseases. Although the properties of NSAIDs may vary slightly between the diverse classes and generations, the main mechanism of action involves inhibition of Cyclo-Oxygenase (COX) in various organs. $\mathrm{COX}$ is the enzyme that converts Arachidonic Acid (AA) to form prostanoids, which are essential biological mediators including Prostaglandins (PG) and Thromboxanes (TX). In 1990, two decades after the discovery of COX, it was revealed that COX exists as two isoforms, COX-1 and COX-2 (Meek et al., 2010; Vonkeman and Laar, 2010). In brief, COX-1 is a constitutive enzyme found in many organs under normal conditions, while COX-2 is an enzyme up-regulated during inflammatory processes. Additionally in 2002, the third COX isoform (COX-3) was discovered. It is encoded by the same gene as COX-1, but COX-3, as a clinical target, is yet to be fully understood (Botting, 2003; Perrone et al., 2010).

In general, COX-1 is thought to be beneficial to the body's homeostasis with functions including maintenance of mucosal epithelium integrity, thus, its inhibition readily leads to gastric ulcers (Buvanendran, 2012). Inhibition of COX-2 only could decrease production of prostanoids such as $\mathrm{PGE}_{2}$ and $\mathrm{PGI}_{2}$ that are just involved in inflammatory and pathological processes, as well as ameliorate pain generation (Agarwal et al., 2009). Therefore, many clinical trials with NSAIDs focus on the selective inhibition of COX-2 enzymes because of the superior safety profile resulting from the COX-1 sparing effect.

Nowadays, there is a growing interest in animal welfare. Owners consider their pets as members of their families. The changed breeding environment and extended life span of pets has meant that they are predisposed to an extended spectrum of diseases for which owners are demanding a higher level of care. These trends have been an impetus for the development San Piero a Grado 56010 Pisa, Italy 
of more effective and innovative veterinary therapies (Giorgi, 2012; Giorgi et al., 2012a; Giorgi and Yun, 2012). However, veterinarians still have a reduced drug armamentarium compared to their human counterparts, thus, many studies have been conducted on the use of human medicine in the veterinary field (Giorgi et al., 2012b; Lavy et al., 2011). As use of selective COX-2 inhibitors (coxibs) became more prominent in human medicine, it followed that many selective inhibitors were introduced into clinical use for the veterinary market. Nowadays, many pharmaceutical companies have their own coxib drugs ("me too" drugs) and some of these active ingredients have been recently launched on the veterinary market.

However, animal species differences in factors such as the sensitivity and disposition of certain drugs could evoke unexpected results if they are used without any understanding of the drugs' behaviour in the target species (Martignoni et al., 2006; Giorgi et al., 2011; Toutain et al., 1997). In addition, to the best of the Authors' knowledge, the cardiovascular effects of coxibs during protracted therapy have not described in animals. In contrast, in the human field, coxibs have been reported to produce adverse effects on cardiovascular system such as thrombotic disorders including cerebral vascular events and myocardial infarction (Cairns, 2007; Batlouni, 2010). Furthermore, animals can be more sensitive to coxibs than humans due to differences in drug metabolism, absorption and enterohepatic recirculation (Bergh and Budsberg, 2005). For these reasons, knowing the pharmacological properties, pharmacokinetic/pharmacodynamic and safety profile of each drug is essential in order to use veterinary coxibs appropriately.

\subsection{Classification of Coxibs}

The coxibs are a subclass of NSAID which have a COX-1 sparing effects. Because of steric hindrance, the COX-1 active site is smaller than that of COX-2. The bulky structure of coxibs restricts their inhibition of COX-1 but allows for complete inhibition of the COX-2 pathway. The classification of NSAIDs is expressed as COX-2 selective, COX-2 specific, or COX-2 preferential. This indicates the drug selectivity for COX2 and it is determined through calculation of the inhibitory concentration $\left(\mathrm{IC}_{50}\right)$ COX-1:COX-2 ratio (Bergh and Budsberg, 2005; Vane and Warner, 2000). However, these ratios have not been fully quantified and ratios for the same compound can be inconsistent, as the assays used were considerably different (Livingston, 2000; Pairet and Ryn, 1998).
Coxibs are regarded as a third generation of NSAIDs (Sternon, 2001). In the human field, several coxibs have been launched. The first to be launched were rofecoxib and celecoxib, these have been categorized as first generation. The newest active ingredients (valdecoxib, parecoxib, etoricoxib and lumiracoxib) have been classified as second generation and possess a stronger selectivity for the COX-2 enzyme inhibition (Stichtenoth, 2004; Andersohn et al., 2006). In veterinary medicine deracoxib (2002), firocoxib (2007), mavacoxib (2008) and robenacoxib (2009) have been introduced for animal use (Bergh and Budsberg, 2005). Recently, cimicoxib (2011) has also been introduced for the veterinary market from the human field (Emmerich, 2012).

\subsection{Deracoxib}

Deracoxib (Deramaxx ${ }^{\circledR}$; Novartis) was the first coxib to be approved in veterinary medicine (Papich, 2008). Deracoxib contains a sulfonamide moiety. Chemically it is a 4-[3-(difluoromethyl)-5-(3-fluoro-4methoxyphenyl)-1H-pyrazole-1-yl] benzenesulfonamide and its molecular weight is $397.38 \mathrm{~g} \mathrm{moL}^{-1}$. Deracoxib is categorized as a diarylheterocycle drug, these exert a time-dependent pseudo-irreversible inhibition of COX-2 (Walker et al., 2001). Deracoxib was initially approved for postoperative orthopedic pain in dogs at 3-4 mg kg-1 by oral (PO) daily dose for a maximum of 7 days. In 2003, deracoxib was also approved for chronic administration at a dosage of $1-2 \mathrm{mg} \mathrm{kg}^{-1}$ PO once daily (Smith, 2003).

In in vitro evaluations, among the coxibs, deracoxib was determined as a highly selective COX-2 inhibitor with a COX-1/COX-2 ratio of 1275 in purified enzymes assay (Gierse et al., 2002). However when tested using canine whole blood, the COX-1/COX-2 ratio was only 12 (McCann et al., 2004). This inconsistency resulted from the different types of cells with different cell conditions being used in each assay (Vane and Botting, 1995).

In another study using dogs, deracoxib showed the same degree of COX-1 and COX-2 inhibition as carprofen (COX-2 preferential drug), despite a wide variation of COX-1/COX-2 inhibitory ratios between the two drugs being found in in vitro assays (Sessions et al., 2005). These discordance results between in vivo and in vitro studies suggest that the in vitro results do not provide a quantitative measure of difference in efficacy or safety (Papich, 2008).

In the pharmacokinetic evaluation after oral administration of deracoxib $\left(2 \sim 3 \mathrm{mg} \mathrm{kg}^{-1}\right)$ in dogs, 
deracoxib had a protein binding affinity of over $90 \%$. It also underwent hepatic biotransformation with an elimination half-life of $3 \mathrm{~h}$, using biliary excretion as a major excretion route (Smith, 2003). After high-dose administration (8 $\mathrm{mg} \mathrm{kg}^{-1}$ ) however, a non-linear elimination has been shown: deracoxib loses its COX-2 selectivity and starts to inhibit COX-1 also (DCT, 2003). The nonlinearity at high doses might result from saturation of the metabolizing enzymes. In other species treated with deracoxib including cats $\left(1 \mathrm{mg} \mathrm{kg}^{-1}\right)$ and horses $\left(1 \sim 2 \mathrm{mg} \mathrm{kg}^{-1}\right)$, a longer half-life (7.9 and $12 \mathrm{~h}$, respectively) than dogs was reported (Davis et al., 2011; Gassel et al., 2006). In cats and horses the hepatic enzymes, which participate in biotransformation of deracoxib, may be present at lower concentrations than in dogs and might therefore be saturated at lower concentrations, which leads to the longer half-life (Davis et al., 2011).

Clinical trials in dogs showed that deracoxib (1 2 mg $\mathrm{kg}^{-1}$ PO for 3 days) was able to reduce postoperative pain and inflammation after dental extraction surgery (Bienhoff et al., 2012). In addition, Millis et al. (2002) reported that the administration of deracoxib $(1,3$, or 10 $\mathrm{mg} \mathrm{kg}^{-1}$ PO) was more effective in reducing pain associated with urate crystal-induced synovitis than carprofen (2.2 mg kg $\mathrm{mO}^{-1}$ PO. Deracoxib treatment also showed no significant adverse effects (Millis et al., 2002).

After 28 days of once daily administration of deracoxib (1.6 mg kg-1 PO), it was shown to be safer than aspirin in regards to risk of gastric ulceration in healthy dogs (Sennello and Leib, 2006). In addition, long-term therapy of deracoxib for up to 6 months administered at the labeled dose, was found to be safe and well tolerated in dogs without any significant nephrotoxicity (Roberts et al., 2009). On the contrary, at higher than labeled doses or when given with other NSAIDs or corticosteroids, deracoxib has been found to cause gastrointestinal perforations in dogs (Lascelles et al., 2005).

Even though there has been no significant instances of hypersensitivity reported thus far, the administration of sulfonamide coxibs in animals allergic to sulfonamides should be carefully considered. Indeed it might be likely a cross reaction with other sulfonamides such as antimicrobial or an evocation of hypersensitivity (Shapiro et al., 2003; Sanchez-Borges et al., 2004; Bergh and Budsberg, 2005; Ayuso et al., 2013). The hypersensitivity of sulfonamide coxib such as deracoxib is yet to be confirmed.

\subsection{Firocoxib}

Firocoxib (Previcox ${ }^{\circledR}$; Meriel) was developed specially for the veterinary field (for dogs and horses). It was found to be 350 430 fold more selective for COX-2 than $\mathrm{COX}-1$ in in vitro canine whole blood assays (McCann et al., 2004). Chemically it is a 3cyclopropymethoxy-5,5-dimethyl-4-[4-(methyl sulfonyl) phenyl]-2-(5H)-furanone and its molecular weight is $336.402 \mathrm{~g} \mathrm{moL}^{-1}$. The drug was launched several years ago and in this short time, the pharmacokinetic properties of firocoxib in dogs and horses have already been well established (Kvaternick et al., 2007a; 2007b; Letendre et al., 2008). Firocoxib is available as a chewable tablet oral preparation which has been approved in the European Union for dogs at a once daily administration of $5 \mathrm{mg} \mathrm{kg}$. . In addition, firocoxib, as an oral paste was approved by FDA for the control of pain and inflammation associated with osteoarthritis in horses at $0.1 \mathrm{mg} \mathrm{kg}$-1 once daily (Kvaternick et al., 2007b). In dogs, following PO administration ( $5 \mathrm{mg} \mathrm{kg}^{-1}$ ), firocoxib was well absorbed and eliminated by hepatic metabolism and fecal excretion with an elimination half-life of $8 \mathrm{~h}$ (Kvaternick et al., 2007a). Firocoxib in horses $\left(0.1 \mathrm{mg} \mathrm{kg}^{-1}\right)$ showed a bioavailability of $79 \%$ and an elimination half-life of 30 and $34 \mathrm{~h}$ for oral and intravenous administration, respectively. Due to its lipophilic and non-ionizable nature, firocoxib was widely distributed with a volume of distribution value of $1.7 \mathrm{~L} \mathrm{~kg}^{-1}$ after intravenous administration in horse. Firocoxib showed a longer halflife compared with other NSAIDs, such as phenylbutazone and flunixin meglumine (Kahn and Line, 2010; Kvaternick et al., 2007b).

A clinical study including 1,000 dogs treated for a 40-day period, reported that withdrawal rate due to development of gastrointestinal side effects was only $2.9 \%$. Over $90 \%$ of investigators and owners rated improved clinical scores after firocoxib treatment (Ryan et al., 2006). In a long-term study over 52 weeks of treatment, a slight increase in withdrawal rate $(5.1 \%)$ was reported due to GI signs (Autefage et al., 2011). Steagall et al. (2007) evaluated the adverse effects of oral firocoxib in healthy dogs for 29 days and found that a dose of $5.3 \pm 0.34 \mathrm{mg} \mathrm{kg}^{-1}$ of firocoxib did not cause any adverse effects on the GI tract or serum biochemical variables and was well tolerated in terms of hematological signs including platelet aggregation and buccal mucosal bleeding time index (Steagall et al., 2007). Firocoxib was found to be effective in a 90 day 
long-term study performed on relatively geriatric dogs (over 7 years) affected by osteoarthritis. The side effects reported (minimal biochemical changes and diarrhea) were thought to be due to age-related deterioration in liver and renal functions (Joubert, 2009). Furthermore, in the sodium urate crystal-induced synovitis model, firocoxib treatment $(5.3 \sim 6.49 \mathrm{mg}$ $\mathrm{kg}^{-1}$ ) resulted in reduced lameness and increased weight-bearing at both 3 and $7 \mathrm{~h}$ post-treatment, as compared with carprofen. Firocoxib efficacy was similar to dogs treated with vedaprofen but without any cardiovascular effects (Hazewinkel et al., 2008).

However, in developmental toxicity studies firocoxib showed embryotoxic and foetotoxic effects in both rats and rabbits, inducing a variety of malformations and anomalies. Consequently firocoxib, as with other coxibs, is contraindicated for use during pregnancy and lactation in dogs. Furthermore, firocoxib had a low safety margin in puppies compared to older dogs. Thus, like other drugs, its use in very young animals requires careful monitoring EMEA, 2006.

\subsection{Mavacoxib}

Mavacoxib (Trocoxil ${ }^{\circledR}$; Pfizer) is a long acting coxib which has a chemical structure of 4-[5-(4-fluorophenyl)3-(trifluoromethyl)-1H-pyrazol-1-yl]-

benzenesulfonamide, it has a molecular weight of $385 \mathrm{~g}$ $\mathrm{moL}^{-1}$ and it acts as a preferential rather than selective COX-2 inhibitor if compared with carprofen. It is approved for the treatment of canine osteoarthritis requiring long-term treatment between 1 and 7 months EMEA, 2008. Mavacoxib is produced in a diverse range of tablets $(6,20,30,75$ and $90 \mathrm{mg})$ as an oral chewable form. Unlike other coxibs, mavacoxib is recommended for monthly administration at $2 \mathrm{mg} \mathrm{kg}^{-1}$ because of its long half-life. In order to achieve steady-state concentrations, it is recommended that mavacoxib is administered with a 2-week interval between the first and second dose with monthly dosing thereafter.

The pharmacokinetics profile of mavacoxib has been well described in Beagle dogs (Cox et al., 2010). It showed significant low clearance rate $(2.7 \mathrm{~mL} / \mathrm{h} / \mathrm{kg})$ with a large volume of distribution $(1.6 \mathrm{Lkg})$ in experimental intravenous administration. Especially in terminal halflife, all PO treated Beagle dogs $(n=63)$ showed an average value of 16.6 days with individual values ranging from 7.9 to 38.8 days. The half-life differences between individuals should be considered as a significant factor in the use of this drug. In fact, in individuals demonstrating a poor elimination rate this drug could evoke cumulative side effects. Moreover, it has been reported that food intake significantly affects mavacoxib absorption. The administration of mavacoxib $\left(4 \mathrm{mg} \mathrm{kg}^{-1}\right)$ in fasted and fed dogs resulted in a bioavailability of 46.1 and $87.4 \%$ respectively. In field trials, mavacoxib showed a terminal elimination plasma half-life of 44 days in the target population, however $5 \%$ of dogs had an extended half-life of 80 days. In addition, most animals treated with $2 \mathrm{mg} \mathrm{kg}$, maintained trough plasma mavacoxib concentrations associated with efficacy (Cox et al., 2011).

As the safety profile has not been established in reproductive toxicity, application of mavacoxib to pregnant or breeding animals should be avoided. Furthermore, this kind of drug, which has a long halflife, should be carefully handled because of the potential for prolonged exposure.

\subsection{Robenacoxib}

Robenacoxib (Onsior $^{\circledR}$; Norvatis) is a coxib which has been developed solely for use in veterinary medicine and is the only approved coxib in cats available as a tablet as well as injectable form (King et al., 2009). It is recommended at a dose of $1 \sim 2 \mathrm{mg} \mathrm{kg}^{-1}$ once daily for both species. It has a chemical structure of 5-ethyl2-[(2, 3, 5, 6-tetrafluorophenyl)amino]-phenyl acetic acid and a molecular weight of 327.27. Robenacoxib is a weak acidic drug ( $\mathrm{pKa} 4.7$ ) which has high protein-binding affinity ( $>98 \%$ in dogs) (Jung et al., 2009). In the in vitro COX-2 selectivity comparative study in dogs with whole blood assay, the $\mathrm{IC}_{50}$ ratio (COX-1:COX-2) was highest in robenacoxib (128.8) when compared to other NSAID such as deracoxib (48.5), nimesulide (29.2) and meloxicam (7.3) (King et al., 2010). In cats, robenacoxib also showed more COX-2 selectiveness (32.2) compared with diclofenac (3.9) and meloxicam (2.7) (Schmid et al., 2010a).

Previous studies have revealed its pharmacokinetic properties via different administration routes including, intravenous, subcutaneous and oral administration in the dog and cat (Jung et al., 2009; Pelligand et al., 2012). In dogs, robenacoxib showed good bioavailability after oral $(84 \%)$ and subcutaneous $(88 \%)$ administration with a short blood half-life of $1 \mathrm{~h}$ (Jung et al., 2009). In addition, Silber et al. (2010) revealed that robenacoxib remained longer in inflamed synovial joints than blood. The anatomically focused persistence of robenacoxib may be triggered by its weak acidity and high proteinbinding affinity. In an inflamed area, the blood supply is increased and $\mathrm{pH}$ has become mildly acidic. These 
alterations allow robenacoxib to enter cells more readily than under normal conditions. The ion-trapping due to the $\mathrm{pH}$ change slows release of the drug and as a result, intracellular drug concentrations increase (Brune and Furst, 2007).

In a clinical study, Schmid et al. (2010b) reported that $\mathrm{SC}$ injection of robenacoxib exerted analgesic and antiinflammatory effects in the urate synovitis model at dosages of $0.25-4 \mathrm{mg} \mathrm{kg}^{-1}$ without COX-1 inhibition (Schmid et al., 2010b). In comparison with carprofen, robenacoxib also demonstrated good efficacy in field trials when given once daily (Reymond et al., 2012). Furthermore, robenacoxib provided similar efficacy and tolerability to meloxicam in controlling perioperative pain and inflammation in dogs (Gruet et al., 2011). In cats after ovariohysterectomy surgery, SC injected robenacoxib (2 $\mathrm{mg} \mathrm{kg}^{-1}$ ) provided a greater analgesic effect for up to $24 \mathrm{~h}$ compared to buprenorphine (Staffieri et al., 2013). According to the study from King et al. (2012), as expected, robenacoxib had an excellent safety profile in young healthy cats when administered at daily dosages up to $10 \mathrm{mg} \mathrm{kg}^{-1}$ for 28 days and up to $20 \mathrm{mg} \mathrm{kg}^{-1}$ for 42 days (King et al., 2012). Also in dogs, robenacoxib showed high safety index without any relevant toxicity with daily dosages as high as $40 \mathrm{mg} \mathrm{kg}^{-1}$ for one month and $10 \mathrm{mg} \mathrm{kg}^{-1}$ for 6 months (King et al., 2011). This proven safety of robenacoxib may result from its high COX-2 selectivity and rapid central compartment clearance with longer residence at inflamed sites (King et al., 2012). However there is no data on reproductive toxicity and robenacoxib should not be used in pregnant or breeding animals.

\subsection{Cimicoxib}

Cimicoxib (Cimalgex ${ }^{\circledR}$; Vetoquinol) is a novel imidazole derivative coxib and a highly selective COX-2 inhibitor, that has recently been launched (Emmerich, 2012). Chemically it is a 4-[4-Chloro-5-(3-fluoro-4methoxyphenyl)-1H-imidazol-1-yl]benzenesulfonamide and its molecular weight is $381.809 \mathrm{~g} \mathrm{moL}^{-1}$. Although it was originally developed to treat depression and schizophrenia, this compound showed good oral activity when tested in experimental models of acute and chronic inflammation and pain (Haroon et al., 2012). After some years of human clinical studies on its anti-inflammatory and analgesic properties, cimicoxib was redirected from the human to the veterinary field.

Cimicoxib is available as chewable oral tablets licensed for dogs as a once daily administration given at a dose of $2 \mathrm{mg} \mathrm{kg}^{-1}$. Due to its recent release, there is very little published data available. Recently an analytical method for cimicoxib pharmacokinetic study has been published (Giorgi et al., 2013). Sorbera and Ramis (2004) found that cimicoxib was more metabolically stable than celecoxib. In humans, cimicoxib undergoes demethylation and a subsequent conjugation reaction, the demethylated metabolite of cimicoxib has been found to be inactive in both COX-1 and COX-2 activity assays. In rats after oral and i.v. administrations, biliary excretion was the major route of elimination. 70 and $30 \%$ of the Cimicoxib dose was excreted in the feces and urine respectively. In Beagle dogs, the bioavailability was $75 \%$ following oral administration $\left(1 \mathrm{mg} \mathrm{kg}^{-1}\right)$ with $\mathrm{t}_{\max }$ of $2 \mathrm{~h}$ and $\mathrm{t}_{1 / 2}$ of $7 \mathrm{~h}$. Like in rats, biliary/intestinal excretion was the major route of elimination in Beagle dogs and cimicoxib was extensively metabolized, as $<0.2 \%$ unchanged drug was detected (Sorbera and Ramis, 2004). In an in vivo inflammatory acute pain model study, $10 \mathrm{~h}$ after administration $\left(2 \mathrm{mg} \mathrm{kg}^{-1}\right)$ the plasma concentrations were above a level of $100 \mathrm{ng} \mathrm{\textrm {Ml } ^ { - 1 }}$ (the $\mathrm{EC}_{50} / \mathrm{IC}_{50}$ values varied between 216 and $452 \mathrm{ng} \mathrm{mL}$ for different parameters) in six out of ten animals. At $24 \mathrm{~h}$, the concentrations are lower than the stated $\mathrm{EC}_{50} / \mathrm{IC}_{50}$ values in all animals. Considering the estimated differences in bioavailability and correcting for non-linear PK, it appeared that the effect of cimicoxib lasted for approximately $10-14 \mathrm{~h}$ in the simulated inflammatory acute pain model EMEA, 2009. In addition, the noninferiority study where it was compared with firocoxib confirmed that cimicoxib reduced the clinical signs of disease including lameness, pain, locomotor disturbance and oedema in dogs with chronic osteoarthritis during the 90 days of the follow up study. Furthermore, compared with carprofen, cimicoxib was also effective in peri-operative pain control in orthopaedic or soft tissue surgery during the first $24 \mathrm{~h}$ after surgery EMEA, 2009.

In a 26 week tolerance study with Beagle dogs, it was demonstrated that adverse effects occur on the gastrointestinal tract and to a lesser extent the kidney especially papillary necrosis at higher doses (10 mg $\left.\mathrm{kg}^{-1}\right)$. However, there were no significant adverse signs in the recommended dose group $\left(2 \mathrm{mg} \mathrm{kg}^{-1}\right)$ and notably, there were no cardiovascular events. The reproductive toxicity study with rabbits however, revealed that the cimicoxib affects fertility and fetal development. Since there are no data in pregnant bitches, "caution" or "cimicoxib is contraindicated in" is needed in breeding, pregnant and lactating dogs EMEA, 2009. 


\section{CONCLUSION}

It is complicated work to make firm distinctions between preferential and selective COX inhibition or between nonselective and preferential inhibition. This is because 1 . Potency ratios (COX-1:COX-2) vary widely according to experimental conditions both within and between laboratories, 2 . the ratio calculated may vary depending on whether it is based on $50,80,95$ or some other percentage inhibition and 3. apparent species differences in inhibition ratios (Lees et al., 2004; Giraudel et al., 2009). However, classification of coxibs is mostly academic and for the purposes of drug categorization. The most important thing is to understand the pharmaco-physiological properties of each coxib in order to make the appropriate choice for each situation. In addition, to secure the expanded list of drugs for veterinary use, trials for adaptation should be on going.

\section{ACKNOWLEDGEMENT}

Researchers acknowledged to Dr H. Owen (University of Queensland, Australia) the English editing of the manuscript.

\section{REFERENCES}

Agarwal, S., G.V. Reddy and P. Reddanna, 2009. Eicosanoids in inflammation and cancer: The role of COX-2. Expert Rev. Clin. Immunol., 5: 145-165. DOI: 10.1586/1744666X.5.2.145

Andersohn, F., S. Suissa and E. Garbe, 2006. Use of first- and second-generation cyclooxygenase-2selective nonsteroidal antiinflammatory drugs and risk of acute myocardial infarction. Circulation, 113: 1950-1957.

DOI:

10.1161/CIRCULATIONAHA.105.602425

Autefage, A., F.M. Palissier, E. Asimus and C. PepinRichard, 2011. Long-term efficacy and safety of firocoxib in the treatment of dogs with osteoarthritis. Vet. Rec., 168: 617-617. DOI: 10.1136/vr.d1456

Ayuso, P., J.A. Cornejo-Garcia, M. Blanca-López, I. Doña and M.J. Torres et al., 2013. Advanced phenotyping in hypersensitivity drug reactions to NSAIDs. Clin. Exp. Allergy. DOI: 10.1111/cea.12140

Batlouni, M., 2010. Nonsteroidal anti-inflammatory drugs: Cardiovascular, cerebrovascular and renal effects. Arq. Bras. Cardiol., 94: 556-563. DOI: 10.1590/S0066-782X2010000400019
Bergh, M.S. and S.C. Budsberg, 2005. The coxib NSAIDs: Potential clinical and pharmacologic importance in veterinary medicine. J. Vet. Intern. Med., 19: 633-643. DOI: 10.1892/08916640(2005)19[633:TCNPCA]2.0.CO;2

Bienhoff, S.E., E.S. Smith, L.M. Roycroft and E.S. Roberts, 2012. Efficacy and safety of deracoxib for control of postoperative pain and inflammation associated with soft tissue surgery in dogs. Vet. Surg., 41: 336-344. DOI: 10.1111/j.1532950X.2011.00942.x

Botting, R., 2003. COX-1 and COX-3 inhibitors. Thromb. Res., 110: 269-272. DOI: 10.1016/S00493848(03)00411-0

Brune, K. and D.E. Furst, 2007. Combining enzyme specificity and tissue selectivity of cyclooxygenase inhibitors: Towards better tolerability? Rheumatology, 46: 911-919. DOI: 10.1093/rheumatology/kem070

Buvanendran, A., 2012. Nonsteroidal AntiInflammatory Drugs. In: Comprehensive Treatment of Chronic Pain by Medical, Interventional and Behavioral Approaches, Deer, T.R., M.S. Leong, A. Buvanendran, V. Gordin and S.J. Panchal (Eds.), Springer, New York, ISBN-10: 1461415594, pp: 35-44.

Cairns, J.A., 2007. The coxibs and traditional nonsteroidal anti-inflammatory drugs: A current perspective on cardiovascular risks. Can. J. Cardiol., 23: 125-131. PMID: 17311118

Cox, S.R., S. Liao, M. Payne-Johnson, R.J. Zielinski and M.R. Stegemann, 2011. Population pharmacokinetics of mavacoxib in osteoarthritic dogs. J. Vet. Pharmacol. Ther., 34: 1-11. DOI: 10.1111/j.1365-2885.2010.01183.x

Cox, S.R., S.P. Lesman, J.F. Boucher, M.J. Krautmann and B.D. Hummel et al., 2010. The pharmacokinetics of mavacoxib, a long-acting COX-2 inhibitor, in young adult laboratory dogs. J. Vet. Pharmacol. Ther., 33: 461-470. DOI: 10.1111/j.1365-2885.2010.01165.x

Davis, J.L., J.F. Marshall, M.G. Papich, A.T. Blikslager and N.B. Campbell, 2011. The pharmacokinetics and in vitro cyclooxygenase selectivity of deracoxib in horses. J. Vet. Pharmacol. Ther., 34: 12-16. DOI: 10.1111/j.1365-2885.2010.01185.x

DCT, 2003. FDA freedom of information summary.

Dubin, A.E. and A. Patapoutian, 2010. Nociceptors: The sensors of the pain pathway. J. Clin. Invest., 120: 3760-72. DOI: $10.1172 /$ JCI42843 
Emmerich, I.U., 2012. New drugs for small animals in 2011. Tierarztl. Prax. Ausg. K. Kleintiere. Heimtiere., 40: 351-362. PMID: 23076019

Gassel, A.D., K.M. Tobias and S.K. Cox, 2006. Disposition of deracoxib in cats after oral administration. J. Am. Anim. Hosp. Assoc., 42: 212217. PMID: 16611933

Gierse, J.K., N.R. Staten, G.F. Casperson, C.M. Koboldt and J.S. Trigg et al., 2002. Cloning, expression and selective inhibition of canine cyclooxygenase- 1 and cyclooxygenase-2. Vet. Ther., 3: 270-280. PMID: 12447834

Giorgi, M. and H. Yun, 2012. Pharmacokinetics of mirtazapine and its main metabolites in Beagle dogs: A pilot study. Vet. J., 192: 239-241. DOI: 10.1016/j.tvj1.2011.05.010

Giorgi, M., 2012. Veterinary pharmacology: Is it still pharmacology's cinderella? Clin. Exp. Pharmacol., 2: 103 .

Giorgi, M., A. Meizler and P.C. Mills, 2012a. Pharmacokinetics of the novel atypical opioid tapentadol following oral and intravenous administration in dogs. Vet. J., 194: 309-313. DOI: 10.1016/j.tvj1.2012.05.019

Giorgi, M., B. Cuniberti, G. Ye, R. Barbero and M. Sgorbini et al., 2011. Oral administration of tepoxalin in the horse: A PK/PD study. Vet. J., 190: 143-149. DOI: 10.1016/j.tvj1.2010.09.013

Giorgi, M., G. Saccomanni, S. Del Carlo, C. Manera and E. Lavy, 2012b. Pharmacokinetics of intravenous and intramuscular parecoxib in healthy Beagles. Vet. J., 193: 246-250. DOI: 10.1016/j.tvj1.2011.11.005

Giorgi, M., T.W. Kim, A. Sabac, M.R. Rouinid and H.I. Yun et al., 2013. Detection and quantification of cimicoxib, a novel COX-2 inhibitor, in canine plasma by HPLC with spectrofluorimetric detection: Development and validation of a new methodology. J. Pharmaceutical Biomed. Anal., 83: 28-33. DOI: 10.1016/j.jpba.2013.04.024

Giraudel, J.M., Toutain, P.L., King, J.N. and Lees, P., 2009. Differential inhibition of cyclooxygenase isoenzymes in the cat by the NSAID robenacoxib. J. Vet. Pharmacol. Ther., 32: 31-40. DOI: 10.1111/j.1365-2885.2008.01031.x

Gruet, P., W. Seewald and J.N. King, 2011. Evaluation of subcutaneous and oral administration of robenacoxib and meloxicam for the treatment of acute pain and inflammation associated with orthopedic surgery in dogs. Am. J. Vet. Res., 72: 184-193. DOI: 10.2460/ajvr.72.2.184
Haroon, E., C.L. Raison and A.H. Miller, 2012. Psychoneuroimmunology neuropsychopharmacology: meets implications of the impact of inflammation on behavior. Neuropsychopharmacol., 37: 137-162. DOI: 10.1038/npp.2011.205

Hazewinkel, H.A., W.E. Van Den Brom, L.F. Theyse, M. Pollmeier and P.D. Hanson, 2008. Comparison of the effects of firocoxib, carprofen and vedaprofen in a sodium urate crystal induced synovitis model of arthritis in dogs. Res. Vet. Sci., 84: 74-79. DOI: 10.1016/j.rvsc.2007.02.005

Joubert, K.E., 2009. The effects of firocoxib (Previcox) in geriatric dogs over a period of 90 days. J. S. Afr. Vet. Assoc., 80: 179-184. DOI: 10.4102/jsava.v80i3.198

Jung, M., P. Lees, W. Seewald and J.N. King, 2009. Analytical determination and pharmacokinetics of robenacoxib in the dog. J. Vet. Pharmacol. Ther., 32: 41-48. DOI: 10.1111/j.1365-2885.2008.01035.x

Kahn, C.M. and S. Line, 2010. The Merck Veterinary Manual. 10th Edn., Merck and Co., Inc., Whitehouse Station, NJ., ISBN-10: 091191093X, pp: 2945.

King, J.N., C. Rudaz, L. Borer, M. Jung and W. Seewald et al., 2010. In vitro and ex vivo inhibition of canine cyclooxygenase isoforms by robenacoxib: A comparative study. Res. Vet. Sci., 88: 497-506. DOI: 10.1016/j.rvsc.2009.11.002

King, J.N., J. Dawson, R.E. Esser, R. Fujimoto and E.F. Kimble et al., 2009. Preclinical pharmacology of robenacoxib: A novel selective inhibitor of cyclooxygenase-2. J. Vet. Pharmacol. Ther., 32: 117. DOI: $10.1111 /$ j.1365-2885.2008.00962.x

King, J.N., J.P. Arnaud, E.I. Goldenthal, P. Gruet and M. Jung et al., 2011. Robenacoxib in the dog: Target species safety in relation to extent and duration of inhibition of COX-1 and COX-2. J. Vet. Pharmacol. Ther., 34: 298-311. DOI: 10.1111/j.13652885.2010.01209.x

King, J.N., R. Hotz, E.L. Reagan, D.R. Roth and W. Seewald et al., 2012. Safety of oral robenacoxib in the cat. J. Vet. Pharmacol. Ther., 35: 290-300. DOI: 10.1111/j.1365-2885.2011.01320.x

Kvaternick, V., M. Pollmeier, J. Fischer and P.D. Hanson, 2007b. Pharmacokinetics and metabolism of orally administered firocoxib, a novel second generation coxib, in horses. J. Vet. Pharmacol. Ther., 30: 208-217. DOI: $10.1111 /$ j.13652885.2007.00840.x 
Kvaternick, V., T. Malinski, J.Wortmann and J. Fischer, 2007a. Quantitative HPLC-UV method for the determination of firocoxib from horse and $\mathrm{dog}$ plasma. J. Chromatogr. B. Analyt. Technol. Biomed. Life Sci., 854: 313-319. DOI: 10.1016/j.jchromb.2007.04.037

Lascelles, B.D., A.T. Blikslager, S.M. Fox and D. Reece, 2005. Gastrointestinal tract perforation in dogs treated with a selective cyclooxygenase-2 inhibitor: 29 cases (2002-2003). J. Am. Vet. Med. Assoc., 227: 1112-1117. DOI: 10.2460/javma.2005.227.1112

Lavy, E., U. Prise, G. Soldani, D. Neri and N. Brandriss et al., 2011. Pharmacokinetics of methylphenidate after oral administration of immediate and sustained-release preparations in Beagle dogs. Vet. J., 189: 336-340. DOI: 10.1016/j.tvj1.2010.07.007

Lees, P., M.F. Landoni, J. Giraudel and P.L. Toutain, 2004. Pharmacodynamics and pharmacokinetics of nonsteroidal anti-inflammatory drugs in species of veterinary interest. J. Vet. Pharmacol. Ther., 27: 479-490. DOI: $10.1111 / \mathrm{j} .1365-$ 2885.2004.00617.x

Letendre, L.T., R.K. Tessman, S.R. McClure, V.J. Kvaternick and J.B. Fischer et al., 2008. Pharmacokinetics of firocoxib after administration of multiple consecutive daily doses to horses. Am. J. Vet. Res., 69: 1399-1405. DOI: 10.2460/ajvr.69.11.1399

Livingston, A., 2000. Mechanism of action of nonsteroidal anti-inflammatory drugs. Vet. Clin. North Am. Small Anim. Pract., 30: 773-781. DOI: 10.1016/S0195-5616(08)70006-8

Martignoni, M., G.M. Groothuis and R.D. Kanter, 2006. Species differences between mouse, rat, dog, monkey and human CYP-mediated drug metabolism, inhibition and induction. Expert Opin. Drug Metab. Toxicol., 2: 875-894. DOI: 10.1517/17425255.2.6.875

McCann, M.E., D.R. Andersen, D. Zhang, C. Brideau and W.C. Black et al., 2004. In vitro effects and in vivo efficacy of a novel cyclooxygenase- 2 inhibitor in dogs with experimentally induced synovitis. Am. J. Vet. Res., 65: 503-512. DOI: 10.2460/ajvr.2004.65.503

Meek, I.L., M.A.F.J. Van De Laar and H.E. Vonkeman, 2010. Non-steroidal anti-inflammatory drugs: An overview of cardiovascular risks. Pharmaceuticals, 3: 2146-2162. DOI: 10.3390/ph3072146
Millis, D.L., J.P. Weigel, T. Moyers and F.C. Buonomo, 2002. Effect of deracoxib, a new COX-2 inhibitor, on the prevention of lameness induced by chemical synovitis in dogs. Vet. Ther., 3: 453-464. PMID: 12584683

Pairet, M. and J.V. Ryn, 1998. Experimental models used to investigate the differential inhibition of cyclooxygenase-1 and cyclooxygenase- 2 by nonsteroidal anti-inflammatory drugs. Inflamm. Res., 2: S93-101. DOI: $10.1007 / \mathrm{s} 000110050289$

Papich, M.G., 2008. An update on Nonsteroidal AntiInflammatory Drugs (NSAIDs) in small animals. Vet. Clin. North Am. Small Anim. Pract., 38: 12431266. DOI: 10.1016/j.cvsm.2008.09.002

Pelligand, L., J.N. King, P.L. Toutain, J. Elliott and P. Lees, 2012. Pharmacokinetic/pharmacodynamic modelling of robenacoxib in a feline tissue cage model of inflammation. J. Vet. Pharmacol. Ther., 35: 19-32. DOI: 10.1111/j.1365-2885.2011.01288.x

Perrone, M.G., A. Scilimati, L. Simone and P. Vitale, 2010. Selective COX-1 inhibition: A therapeutic target to be reconsidered. Curr. Med. Chem., 17: 3769-3805. DOI: 10.2174/092986710793205408

Reymond, N., C. Speranza, P. Gruet, W. Seewald and J.N. King, 2012. Robenacoxib vs. carprofen for the treatment of canine osteoarthritis; A randomized, noninferiority clinical trial. J. Vet. Pharmacol. Ther., 35: $\quad 175-183$. DOI: $10.1111 /$ j.13652885.2011.01297.x

Roberts, E.S., K.A. Van Lare, B.R. Marable and W.F. Salminen, 2009. Safety and tolerability of 3-week and 6-month dosing of Deramaxx((R)) (Deracoxib) chewable tablets in dogs. J. Vet. Pharmacol. Ther., 32: 329-337. DOI: 10.1111/j.13652885.2008.01043.x

Ryan, W.G., K. Moldave and D. Carithers, 2006. Clinical effectiveness and safety of a new NSAID, firocoxib: A 1,000 dog study. Vet. Ther., 7: 119-126. PMID: 16871494

Sanchez-Borges, M., A. Capriles-Hulett and F. Caballero-Fonseca, 2004. Adverse reactions to selective cyclooxygenase-2 inhibitors (coxibs). Am. J. Ther., 11: 494-500. DOI: 10.1097/01.mjt.0000125121.35422.b4

Schmid, V.B., D.E. Spreng, W. Seewald, M. Jung and P. Lees et al., 2010b. Analgesic and anti-inflammatory actions of robenacoxib in acute joint inflammation in dog. J. Vet. Pharmacol. Ther., 33: 118-131. DOI: 10.1111/j.1365-2885.2009.01117.x 
Schmid, V.B., W. Seewald, P. Lees and J.N. King, 2010a. In vitro and ex vivo inhibition of $\mathrm{COX}$ isoforms by robenacoxib in the cat: A comparative study. J. Vet. Pharmacol. Ther., 33: 444-452. DOI: 10.1111/j.1365-2885.2010.01166.x

Sennello, K.A. and M.S. Leib, 2006. Effects of deracoxib or buffered aspirin on the gastric mucosa of healthy dogs. J. Vet. Intern. Med., 20: 1291-1296. DOI: 10.1111/j.1939-1676.2006.tb00741.x

Sessions, J.K., L.R. Reynolds and S.C. Budsberg, 2005. In vivo effects of carprofen, deracoxib and etodolac on prostanoid production in blood, gastric mucosa and synovial fluid in dogs with chronic osteoarthritis. Am. J. Vet. Res., 66: 812-817. DOI: 10.2460/ajvr.2005.66.812

Shapiro, L.E., S.R. Knowles, E. Weber, M.G. Neuman and N.H. Shear, 2003. Safety of celecoxib in individuals allergic to sulfonamide. Drug Saf., 26: 187-195. DOI: 10.2165/00002018-20032603000004

Silber, H.E., C. Burgener, I.M. Letellier, M. Peyrou and M. Jung et al., 2010. Population pharmacokinetic analysis of blood and joint synovial fluid concentrations of robenacoxib from healthy dogs and dogs with osteoarthritis. Pharm. Res., 27: 26332645. DOI: $10.1007 / \mathrm{s} 11095-010-0262-\mathrm{z}$

Smith, S.A., 2003. Deracoxib. Compendium Continu. Educ. Practic. Vet., 25: 452-454.

Sorbera, L.A. and I. Ramis, 2004. Cimicoxib. Antiarthritic, analgesic, COX-2 inhibitor. Drug Future, 29: 325-330. DOI: 10.1358/dof.2004.029.04.790967

Staffieri, F., P. Centonze, G. Gigante, L.D. Pietro and A. Crovace, 2013. Comparison of the analgesic effects of robenacoxib, buprenorphine and their combination in cats after ovariohysterectomy. Vet. J. DOI: $10.1016 /$ j.tvj1.2013.01.018
Steagall, P.V., F.B. Mantovani, T.H. Ferreira, E.S. Salcedo and F.Q. Moutinho et al., 2007. Evaluation of the adverse effects of oral firocoxib in healthy dogs. J. Vet. Pharmacol. Ther., 30: 218-223. DOI: 10.1111/j.1365-2885.2007.00842.x

Sternon, J., 2001. The coxibs, third generation antiinflammatories. J. Pharm. Belg., 22: 100-105. PMID: 11508259

Stichtenoth, D.O., 2004. The second generation of COX2 inhibitors: clinical pharmacological point of view. Mini reviews in medicinal chemistry. Mini Rev. Med. Chem., 4: 617-24. DOI: 10.2174/1389557043403783

Toutain, P.L., A. Ferran and A. Bousquet-Melou, 1997. Species Differences in Pharmacokinetics and Pharmacodynamics. In: Handbook of Experimental Pharmacology, Kavlock, R.J. and G.P. Daston (Eds.), Springer-Verlag, Berlin, New York, ISBN-10: 3540612599. pp: 19-48.

Vane, J.R. and R.M. Botting, 1995. New Insights into the mode of action of antiinflammatory drugs. Inflamm. Res., 44: 1-10. DOI: 10.1007/Bf01630479

Vane, J.R. and T.D. Warner, 2000. Nomenclature for COX-2 inhibitors. Lancet, 356: 1373-1374. DOI: 10.1016/S0140-6736(00)02837-3

Vonkeman, H.E. and M.A.F.J.V.D. Laar, 2010. Nonsteroidal anti-inflammatory drugs: adverse effects and their prevention. Semin. Arthritis Rheu., 39: 294-312. DOI: 10.1016/j.semarthrit.2008.08.001

Walker, M.C., R.G. Kurumbail, J.R. Kiefer, K.T. Moreland and C.M. Koboldt et al., 2001. A threestep kinetic mechanism for selective inhibition of cyclo-oxygenase-2 by diarylheterocyclic inhibitors. Biochem. J., 357: 709-718. DOI: 10.1042/02646021:3570709 